\title{
Development of a Wind Power System on Trucks
}

\author{
Albert Wen-Long Yao*, Chia-Hui Chiu \\ Department of Mechanical and Automation Engineering, National Kaohsiung First University of Science and Technology, Taiwan
}

Copyright $(2015$ by authors, all rights reserved. Authors agree that this article remains permanently open access under the terms of the Creative Commons Attribution License 4.0 International License

\begin{abstract}
Nowadays, the shortage of fossil fuels consuming on vehicles are in an emergent situation. Moreover, the $\mathrm{CO}_{2}$ emissions from transportations make a very negative impact on our environment. Therefore, to develop a renewable energy system for transportations becomes an important issue and draw a lot of attentions from academia and government agency. The aim of this study is to develop a wind power system for vehicles. A novel win turbine blade was designed and developed based on the methods of literature survey, TRIZ theory, and the theory of aerodynamics. Then, the system integration with gear, generator, and charge controller were carried out on a moving vehicle which could convert the wind power into electrical energy for use and storage. This study uses the CFD simulation software of ANSYS CFX to analyze the wind flow field of a truck, and simulate the dynamic status of the wind turbine in different locations. The result shows that the proposed wind power system on vehicles could generate about 300Watts while the vehicles are moving. The simulation result also provides very good evidence that the most appropriate installation position is in the front roof of a truck, where it could generate better efficiency of electricity in this research.
\end{abstract}

Keywords Twisted Vertical Axis Blade, Wind Power System on Vehicles, CFD, TRIZ Theory

\section{Introduction}

Since the industrial revolutions, the automobile industry with internal combustion engine brought people comfortable and convenient life, and it also increased efficiency and generated opportunity for business. On the contrary, the consuming rate of fossil fuels increased dramatically year by year. As a result, it causes the oil market price ascend sharply. This will directly impact the goods and materials for people's livelihood seriously. Thus, all kinds of transportation will face the issues of gas costs and energy saving. By the way, to the environment, $\mathrm{CO}_{2}$ emissions will cause the greenhouse effect, and make global climate and ecological environment anomalous. The amount of $\mathrm{CO}_{2}$ emissions are engaged from the sector of transportation about $20 \%$, while the automobile and motorcycle are engaged more than $80 \%$ of it. According to the reports [3-4], it shows that the mileage accumulation is engaged from the freight transportation about $80 \%$. That is, the freight transportation is the prim culprit of fossil fuels consumption and $\mathrm{CO}_{2}$ emission.

Due to the balance of technology development and lecology concerns, the energy technology becomes a hot topic worldwide. The development of diverse energy resources draws a lot of attentions from academia and government. In 2011, the World Wildlife Fund (WWF) predicts that $95 \%$ of the required global energy will come from renewable energy resources in 2050 [5]. In advanced countries, the governments encourage auto makers and research institutes to develop new vehicles with alternative renewable energy. Among the renewable energy resources, the wind power is the most popular. According to the "Global Wind Energy Report 2009" of World Wind Energy Association (WWEA) and the "Renewable Energy 2010 Global Status Report" of the 21st Century Renewable Energy Policy Network (REN21), the growth of global installed wind power system was $31.7 \%$ in 2009 [6][7]. That is, although the economic regression, the wind power industry is still the fastest growing industry among the alternative energy technologies. Therefore, the application of wind power generation technology into the vehicles would be the most potential and applicable alternative energy resources.

There are several related studies addressed to this issue. Hong [8] proposed the preliminary design process of wind power generation system on vehicles. The result showed that it did increase the storage battery capacity. Zheng [9] also present a similar study with little discussion of losing rate of fuel consumption. He claimed that the maximum of recovery efficiency in fuel consumption could reach $3.22 \%$ in his study. To the study of wind power on vehicle, the "Greenbird", made by Ecotricity in England, utilizes the great wings to drive the car. The Greenbird is the fastest wind power vehicle of the world with speed up to $200 \mathrm{~km} / \mathrm{hr}$ [10]. The "Ventomobile" of Stuttgart University in Germany uses wind power to drive three-wheel bicycle. The dual rotor impellers were set on the roof rack. The maximum speed 
could achieve $24 \mathrm{~km} / \mathrm{hr}$ [11]. Dirk and Stefan [12] developed the first wind power car "Wind Explorer", which drives the kite on electric vehicle by using the lithium-ion battery during the day. While parking or in the evening, the stowed wind power generation system could be set up and generate electricity for storage in the lithium-ion battery.

The aim of this study is to develop a wind power system for trucks. We adopted TRIZ theory to design the wind turbine blade. The blade was made by fiberglass material. The wind power system was integrated and installed on a vehicle to valid the CFD simulation result. The paper is organized as follows: Section 2 reviews the analysis and design theory. Section 3 describes the wind turbine blade design, fabrication, and wind power system integration. Section 4 details the CFD simulation and dynamic analysis. Section 5 shows the verification and results. Section 6 ends with conclusions of this study.

\section{Analysis and Design Theory}

\subsection{Traffic Safety Regulation and Intellectual Property Survey}

\subsubsection{Traffic Safety Regulation of Road}

According to the regulation of the Ministry of Transportation (MOT) of Taiwan, there is no specific traffic law to regulate the installation of wind power generation device for vehicles. However, every re-equipped vehicle should be evaluated by the Department of Motor Vehicle. Therefore, the new design wind power device for trucks should follow the restriction of dimension of vehicles. This restriction becomes the design guideline for the wind power system. The limitation of the overall dimension for vehicle on road is listed in Table 1 [13].

Table1. The restriction of overall size of vehicle.

\begin{tabular}{|c|c|}
\hline & Restriction \\
\hline Length & Not exceed the length of overall vehicle for $30 \%$. \\
\hline Width & Not exceed the width of the vehicle. \\
\hline Height & The maximum height of the overall vehicle is 4 meters. \\
\hline Other & Should be connected with the main construction of vehicle. \\
\hline
\end{tabular}

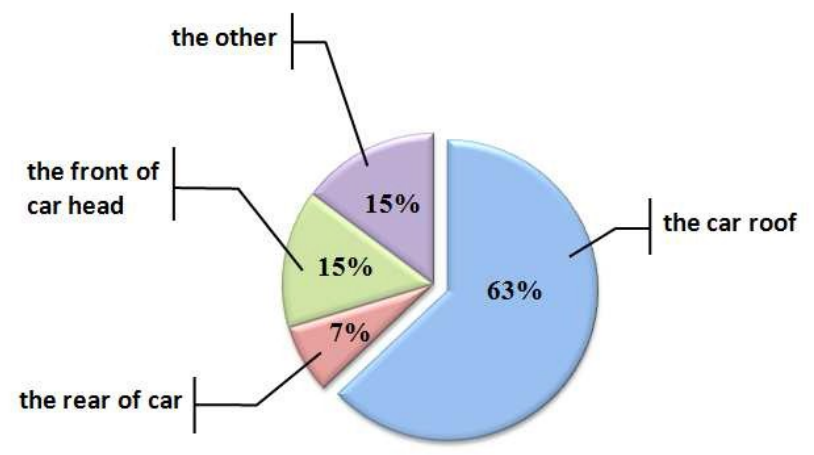

(a)

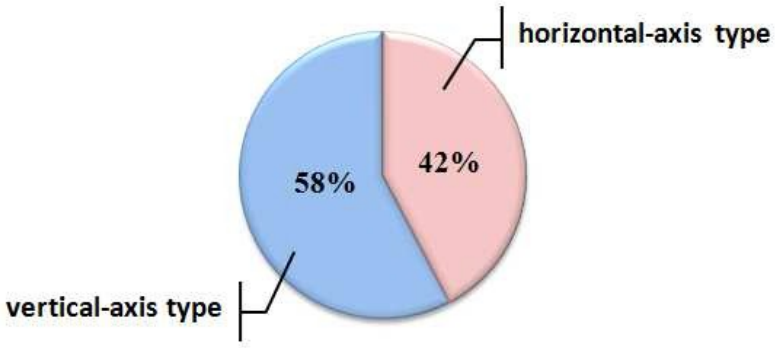

(b)

Figure1. The statistic of patent cases (a) the installed location (b) the types of wind turbines.

\subsubsection{Intellectual Property Survey}

The domestic and international related patent review was investigated by the intellectual property (IP) survey platforms of the Department of Intellectual Property Office, Taiwan, and U.S. Patent and Trademark Office [14-15]. The essential key words include "wind power, wind power generation, airflow, wind, power, turbine, generator, vehicle, and device". In our study, there are 24 patents filed on the wind power equipment for trucks or vehicles. The analysis of installation location and type of wind power system is pictorial illustrated in Figure 1. It shows that the most of the wind power system were installed on the roof of the vehicles and the most popular wind power systems are vertical-axis.

From Figure 1, the case analysis of patent shows that the installed location of wind turbine is mostly outside the vehicle, where the wind power device can utilize the wind energy directly and reduce the energy lost by the car interior and airflow variation. The wind turbines are mostly installed on the roof of vehicles. That is, the wind power turbines can directly absorb the wind and generate power efficiently. The common types of wind turbine rotors are horizontal-axis and vertical-axis. The vertical-axis turbine is a bit of prefer to horizontal-axis turbine. That is, although the horizontal-axis wind turbine has better power generation efficiency, the airflow of horizontal-axis wind turbine is hard to stable while the vehicle is moving. Besides, the horizontal-axis is difficult to utilize wind energy efficiently. Therefore, the vertical-axis rotor is appropriate for wind power vehicle application.

\subsection{TRIZ Aided Problem Solving Technique}

Although a wind power device on vehicle is able to utilize the renewable wind energy, it will cause the car's air resistance increase, too. In order to solve the dilemma of air resistance rising and pressure drag while the vehicle speeds up, the TRIZ aided problem solving technique is employed in this study. TRIZ theory is a theory that considers engineering problems and suggested solutions based on overcoming contradictions. The TRIZ matrix is a database of known solutions able to overcome contradictions [16]. The 40 TRIZ principles are known solutions to solve contradictions. Using these known solutions in new 
problems can bring innovative solutions. The procedure of the 40 TRIZ principles is shown in Figure 2. In this study, we adopt the TRIZ theory to assist identify the causes and effects of the wind turbine blade design. When the problem occurs, the first step is to judge the problems which belong to physical contradiction or technical contradiction. If there is no appropriate parameter or rule in the 39 characteristic parameters of contradiction matrix or 40 creative invention principles, the technical contradiction can be changed into physical contradiction. Using the separation principle to find out the essential components and features, and then seek for the method of problem solving by analogy thinking [16].

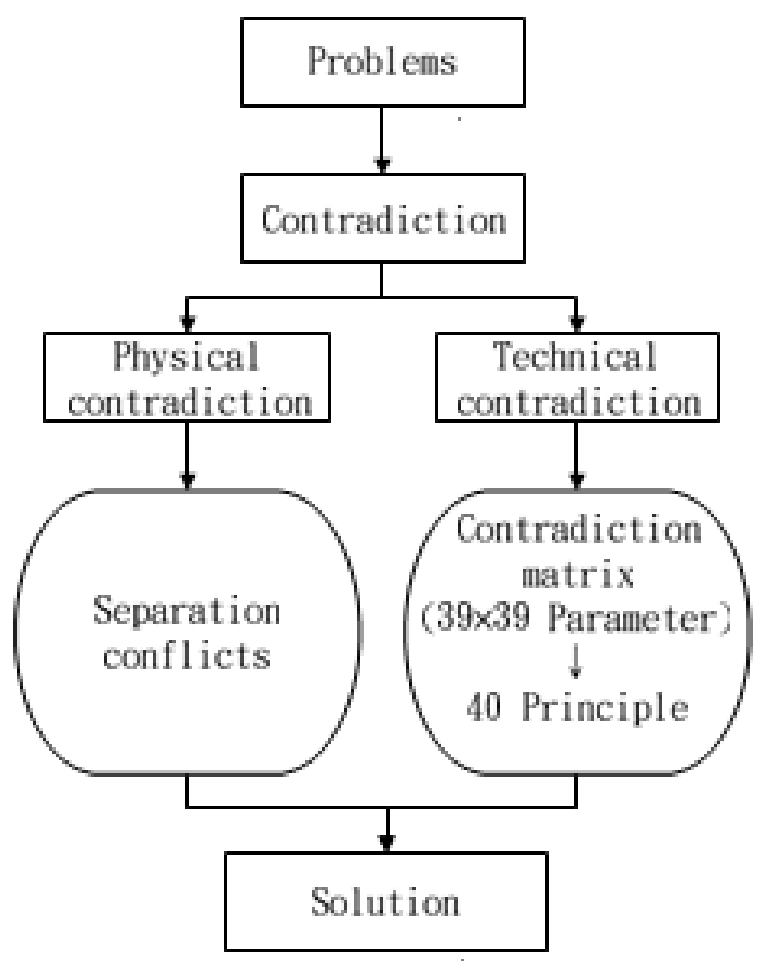

Figure 2. TRIZ theory to solve contradictions flow chart

\subsection{Wind Turbine Aerodynamics}

The wind power system utilizes wind energy acting on the turbine blades to drive the generator for producing electricity. By Betz's Law [17], the maximum efficiency of wind power converting of an ideal wind turbine is about $59.3 \%$ under the situation of no energy losing. This is known as the "Betz limit". However, in practical application, the process of wind power generation system from wind power capturing to electricity converting needs to take the factor of the loss of energy transfer of components and devices into account. It includes many complex factors such as mechanical transmission efficiency, generator efficiency and energy conversion efficiency. The generated electricity is as equation (1). This theory of wind turbine aerodynamic equation is the basis for selecting the size of turbine blade.

$$
P_{\mathrm{WPS}}=\frac{1}{2} \rho A V^{3} C_{p} \times \eta_{T} \eta_{G} \eta_{E}
$$

where $P_{\mathrm{w} P S}$ is the generating capacity of wind power generation system, $\rho$ is air density, $A$ is windward area, $V$ is relative velocity of wind, $C_{p}$ is the power conversion coefficient, $\eta_{T} \eta_{G} \eta_{E}$ is the efficiency of mechanical transmission, generator efficiency and power conversion efficiency.

\section{Blade Design and Fabrication}

\subsection{Shape of Wind Turbine Blade}

In the wind power device, the turbine blade could increase air resistance and pressure drag problems. The turbine blade design needs to balance this cause and effect. In other word, it should overcome the contradictions carefully. Thus, after finding out the 40 inventions principles in contradiction matrix of TRIZ theory, we adopt the most appropriate solution method to set the shape of vertical axis blade. The procedure of the blade shape design is shown in Figure 3.

The air resistance and the pressure drag are influenced by the orthographic projection area of the moving object while the vehicle is traveling. Hence, in the essential improvement of the system characteristics parameters, the "(05) Area of a moving object" refers to parameter of which the blade area of wind turbine on vehicle should be improved. The possible deteriorated characteristics parameters would choose the "(11) Tension/Pressure" as the deteriorated affecting parameters which can cause the air resistance and the pressure drag. In the first run of TRIZ contradiction matrix, the corresponding factors are the four invention principles 10 , 15,28 , and 36. The item "(15) Dynamic principle" is as the direction of problem solving to change the objects properties, characteristics or the external environment in operational stages. However, it is hard to decide how to change the shape of blade. Hence, "(12) Shape" is chosen as the needed improving system characteristics parameters and the possible deteriorated system characteristics parameters is chosen as "(11) Tension/Pressure" for second run in contradiction matrix. Now the contradiction matrix corresponds to the invention principles 10, 14, 15, and 34 . From the item "(14) Spherical principle", the shape of blade can be exactly defined. The shape and surface of blade is crankshaft and spiral instead of linear and flat. That is, our proposed turbine blade design is as twisted vertical axis blades. Several related researches [18-19] also claimed that the twisted blade with longer arm is able to generate higher torque. In addition, the twisted blade could improve the running stability and the capacity of output efficiency. The twisted blade is still able to run in a very low wind speed, like as the typical "Savonius blade" does. 


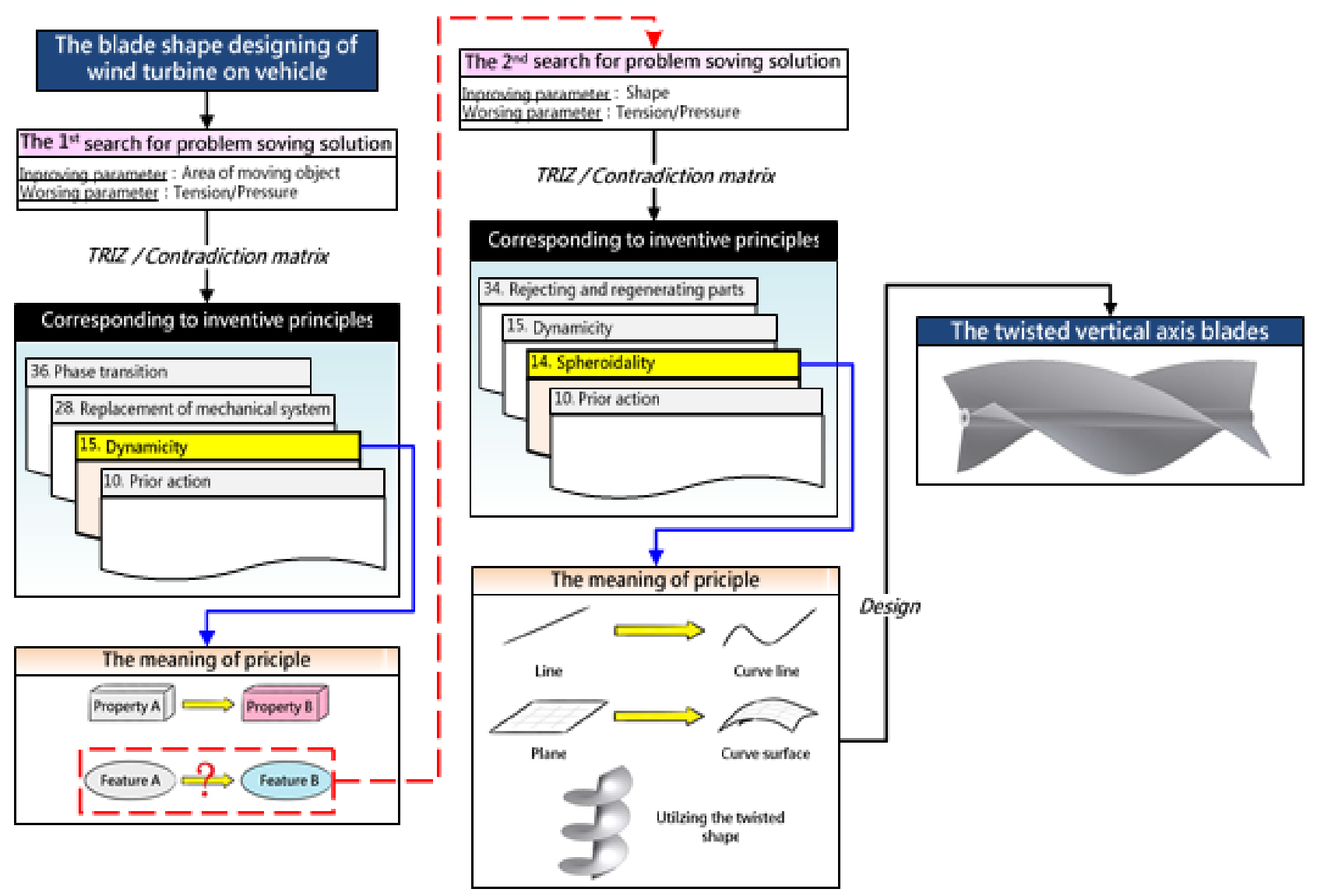

Figure 3. The procedure for sizing the blade shape

\subsection{Size of Wind Turbine Blades}

Our designed wind turbine is vertical axis rotor with three twisted blades. By equation (1), the size of blades can be determined with desired electricity generation of the wind turbine system. The assumptions of external condition are as followed:

a. Reference pressure: $1 \mathrm{~atm}$

b. Air density: $1.184 \mathrm{~kg} / \mathrm{m} 3$

c. Operating temperature: $25^{\circ} \mathrm{C}$

d. Relative wind velocity: $60 \mathrm{~km} / \mathrm{hr}(16.7 \mathrm{~m} / \mathrm{s})$

e. Total efficiency $\eta\left(C_{p} \times \eta_{T} \eta_{G} \eta_{E}\right): 0.25$

f. Power output: 300 Watts

From the above data, the windward area is about $0.43 \mathrm{~m}^{2}$, which can be calculated by equation (1). With the restriction of the width of car roof and space reservation for other components, the rotation radius of wind turbine was designed as $0.18 \mathrm{~m}$ and the length of axis was as $1.15 \mathrm{~m}$, as shown in Figure 4.

\subsection{Wind Power System Integration}

The wind turbine is made of FRP with main features of light weight, high strength, and good plasticity. The blades are twisted from left to right with angle of $180^{\circ}$. The proposed wind turbine drives a 400Watts three-phase permanent-magnet synchronous generator by a gear train with ratio of 100:56. The generator is coupled with a circuitry of voltage stable and overcharge protection. The generated electricity was stored in a battery for truck use later. The proposed wind power system is shown in Figure 5. The overall dimension is $1.43 \mathrm{~m} \times 0.3 \mathrm{~m} \times 2.5 \mathrm{~m}$.

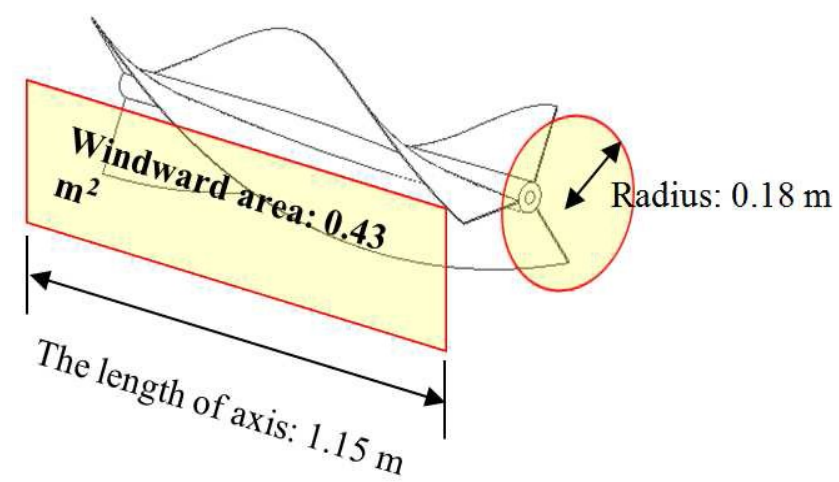

Figure 4. Size of wind turbine blades 


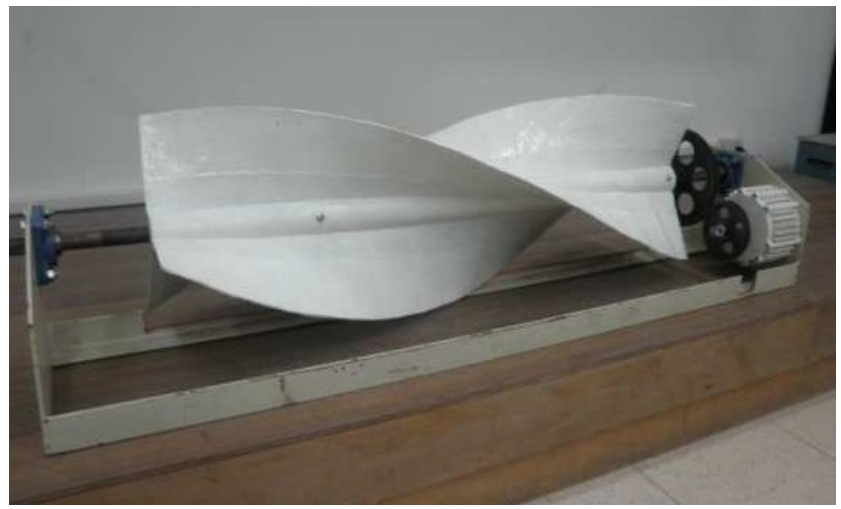

Figure 5. The wind power system for truck with twisted vertical axis blades, generator, and gear train

\section{Numerical Simulation}

\subsection{Modeling and Meshing}

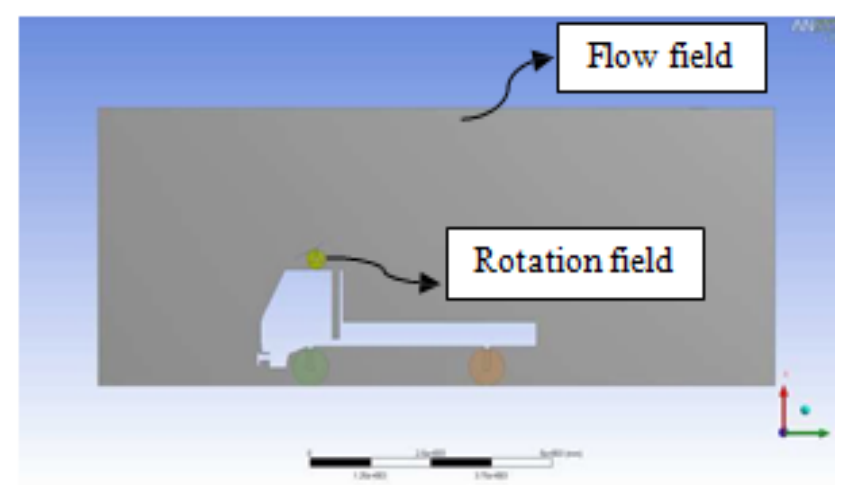

Figure 6. The simulation model with flow field and rotation field

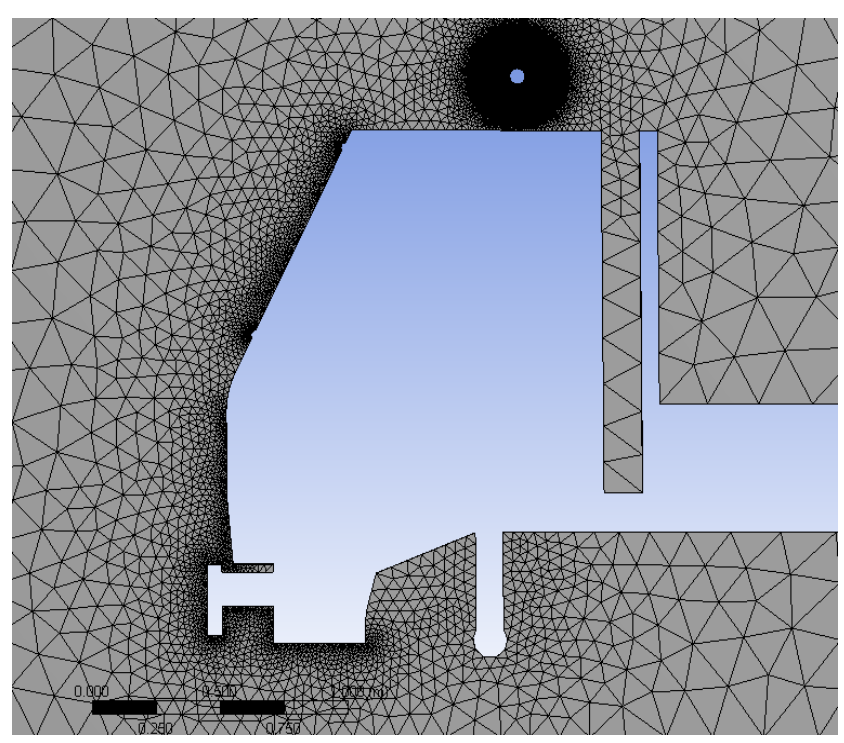

Figure 7. The orthogonal mesh of the model

The Hino 10.5 tons truck is the object for this study. Figure 6 shows the full scale simplified model with a flow field area for simulation analysis. A rotating field was established in the turbine blade rotating area. The length of flow field area is $14 \mathrm{~m} \times 5.5 \mathrm{~m} \times 0.19 \mathrm{~m}$. The mesh of the model is present in Figure 7. It shows that the mesh around the car and turbine is finer than the far area of the analysis model. We adopt the orthogonal mesh for better result in this study.

\subsection{Simulation and Boundary Conditions}

The simulation conditions for CFX are shown in Table 2. The boundary conditions are set as follows: (1) The inlet boundary is in the front of the truck, while the top and rear of the truck model are set for opening boundaries. (2) The trucks, ground, and the boundary of the wind turbine are non-slip wall. (3) The left and right sides of the rotation area and the flow field area are set for symmetric boundary. (4) The movement of the mesh of a rotation area is not designated. (5) The construction of flow field and the model of the interfacial rotation area are transient rotor stator. (6) The reference movement of the mesh of rotation area is not designated. (7) Choose the GGI method as the connection.

Table2. The basic condition setting

\begin{tabular}{|c|c|}
\hline Item & Value \\
\hline Initial time & $0(\mathrm{~s})$ \\
\hline Total step & 2500 \\
\hline $\mathrm{dt}$ & $0.01(\mathrm{~s})$ \\
\hline Wind velocity & $10(\mathrm{~m} / \mathrm{s})$ \\
\hline Reference pressure & $1 \mathrm{~atm}$ \\
\hline Turbulence & k-Epsilon \\
\hline
\end{tabular}

In order to simulate the wind turbine on vehicle on road, the only known condition is the wind velocity, which corresponds to the real flow field situation. An unstable starting way was adopted in this study. That is, the turbine blades were blown by giving flow field speed with the wind velocity. In such a way, the torque of blades will be generated to turn the wind turbine rotating [20]. The torque and the velocity of blades can be illustrated as follows:

$$
\mathrm{T}_{\text {Blades }}=r F=I_{m} \alpha=I_{m} \cdot \frac{d \omega}{d t}=I_{m} \cdot \frac{\left(\omega_{t+1}-\omega_{t}\right)}{d t}
$$

Rearranging equation (2), the angular velocity is obtained as equation (3):

$$
\omega_{t+1}=\omega_{t}+\frac{\mathrm{T}_{\mathrm{Blades}} \cdot d t}{I_{m}}
$$

where $\omega_{t}$ is the angular velocity of the mesh movement; $\mathrm{T}_{\text {Blades }}$ is the torque which is generated by the fluid of the wind turbine blades. The $d t$ is the time variation. The moment of inertia $I_{m}$ can be calculated after defining the material of the model by the engineering drawing software. Then, the rotary angle velocity $\omega_{t+1}$ can be obtained when the wind blows to the blades. 

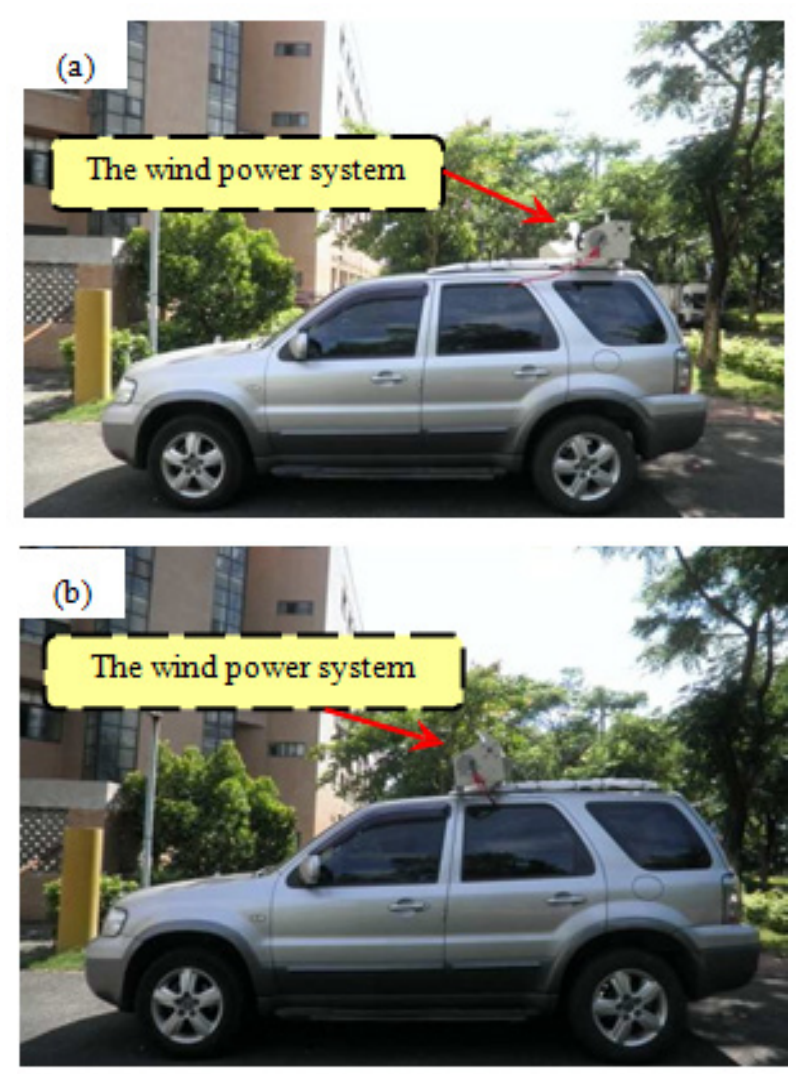

Figure 8. The installed locations of wind turbine system: (a) on the rear roof, and (b) on the front roof

\section{Results and Discussions}

\subsection{Experiments and Results}

In order to evaluate the feasibility and efficiency of the proposed wind power system, we installed this proposed system on two locations of a vehicle. We installed the wind power system on the front roof and the rear roof of the vehicle (See Figure 8). The experimental results are explained with the numerical simulation results of CFD.

In the experiment, five generated electricity data were recorded for every $10 \mathrm{~km} / \mathrm{hr}$ of the relative wind speed. The experiments show that the wind power system installed on the rear roof did not generate any electricity because the turbine did not turn when vehicle is moving. On contradiction, the wind power system installed on the front rood did generate some electricity. Figure 9 shows the wind power curve of different relative wind velocity. The experimental total efficiency is about 0.1 . It is less than 0.15 of the design efficiency. From Figure 9, when the wind velocity is about $82.5 \mathrm{~km} / \mathrm{hr}$, the wind power system can produce about 300 Watts at the 0.1 efficiency curve. The general cut-in speed for small wind turbines is about 3 to $6 \mathrm{~m} / \mathrm{s}$. The cut-in speed of our system is about $6.72 \mathrm{~m} / \mathrm{s}$ because of the self-weight of FRP turbine blades. It needs enough air flow to turn the turbine blades to generate electricity.

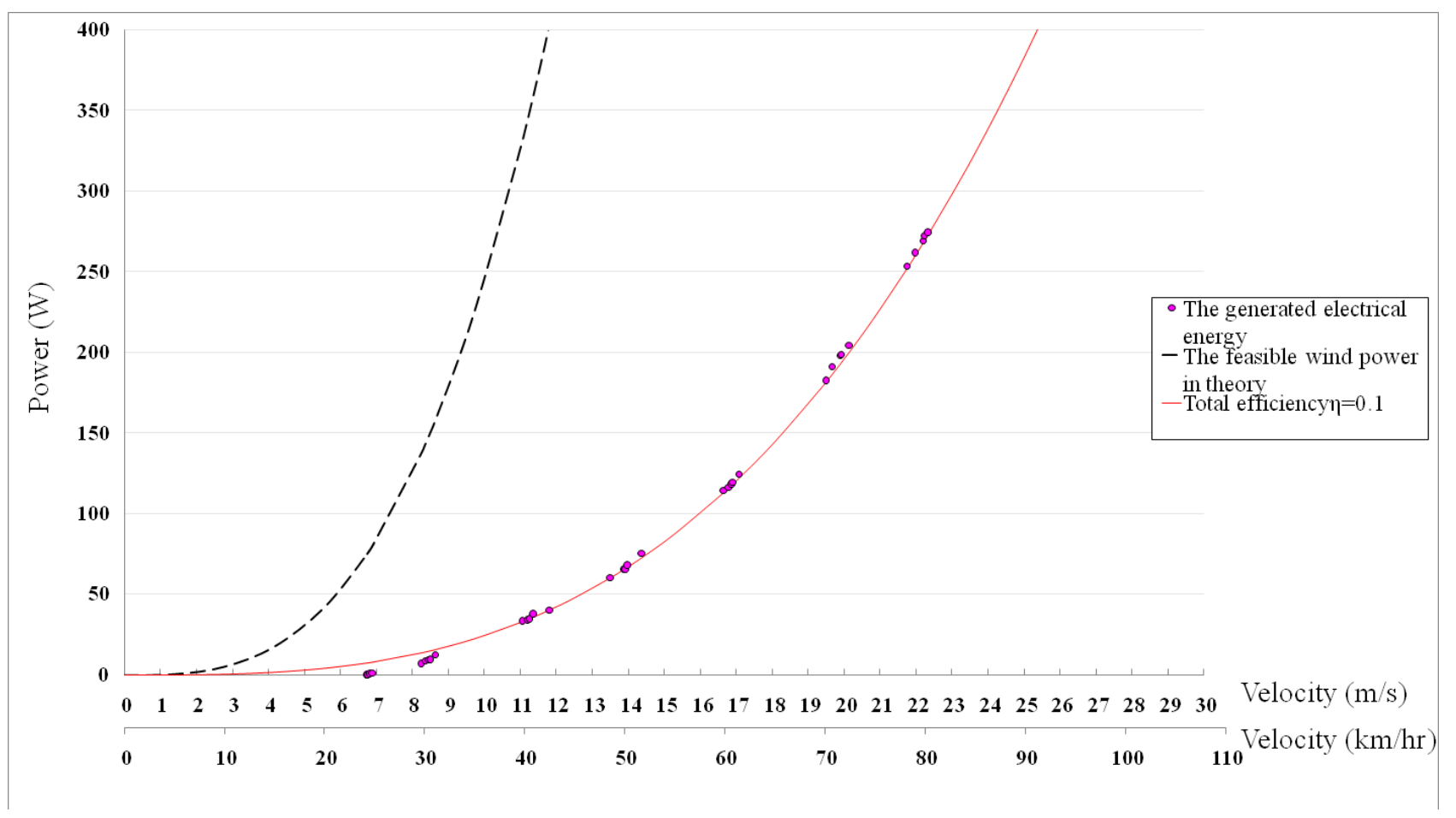

Figure 9. Wind power curve of the wind power system in the front roof of vehicle

\subsection{CFD Simulations and Analysis}

From above experiments, it indicates that the wind power system installed in the rear roof does not generate any power. 
Hence, we started our CFD numerical simulations and analysis to investigate and explain the causes and effects. The simulation condition is with a fixed relative wind velocity of $10 \mathrm{~m} / \mathrm{s}$ simulating as the truck is moving. The variation of rotor angular velocity was observed to determine the stability of the rotation of wind power system.

Case 1: the wind turbine is installed in the rear roof.

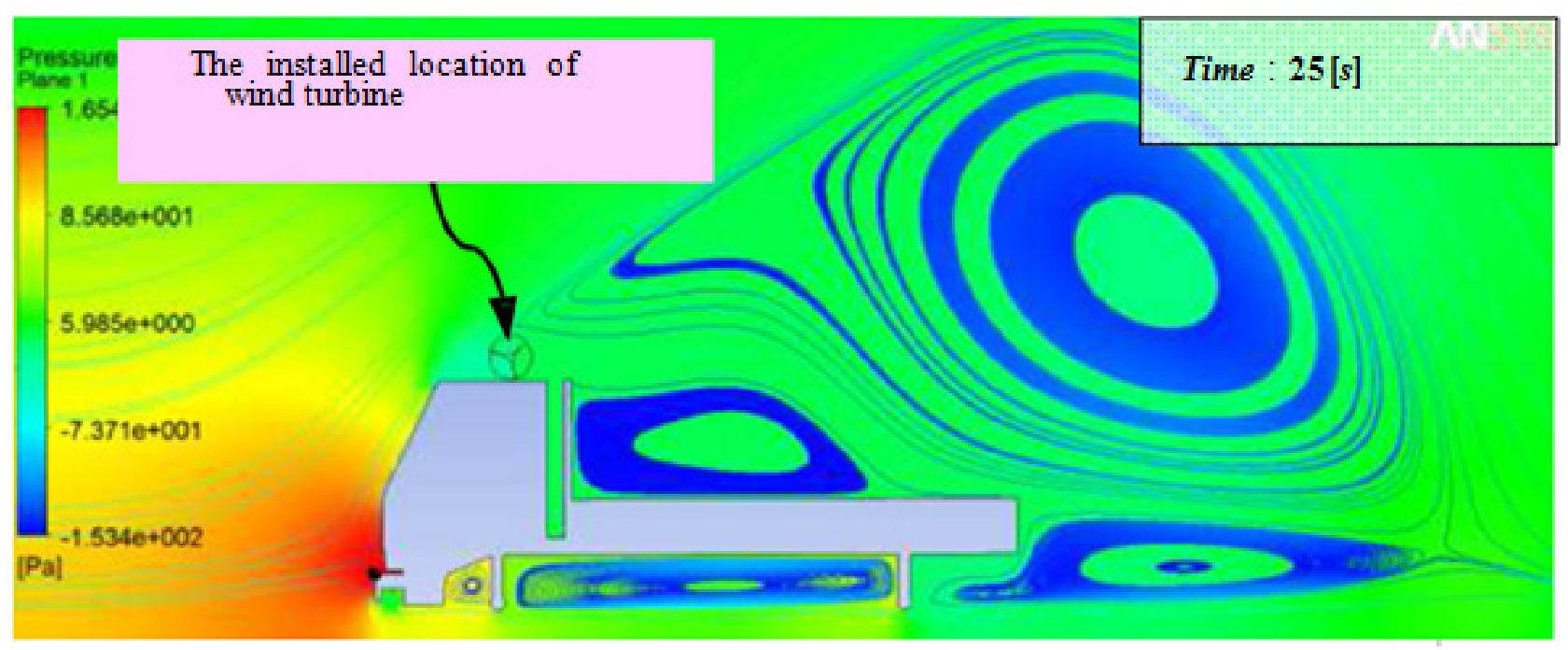

(a)

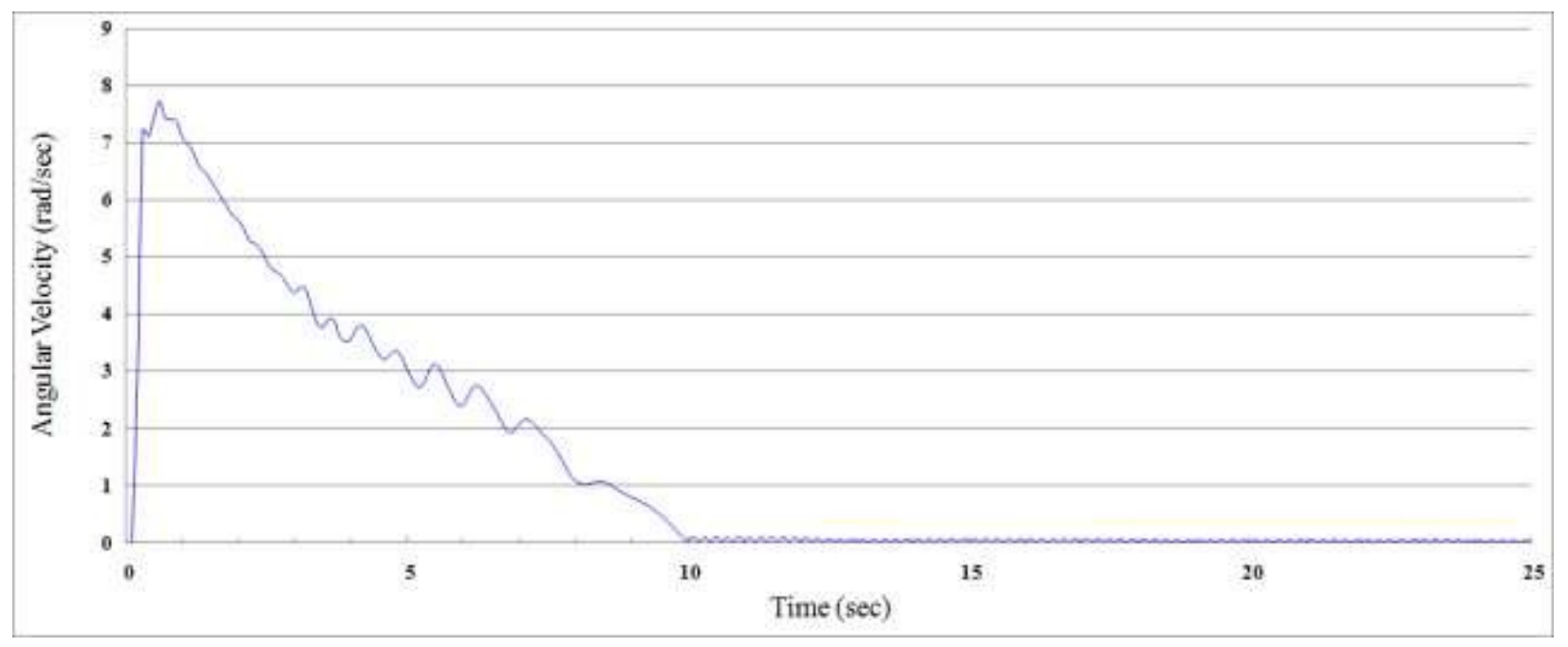

(b)

Figure 10. Turbine installed in the rear roof: (a) the pressure and streamline diagram, (b) the angular speed 
Case 2: the wind turbine is installed in front roof.

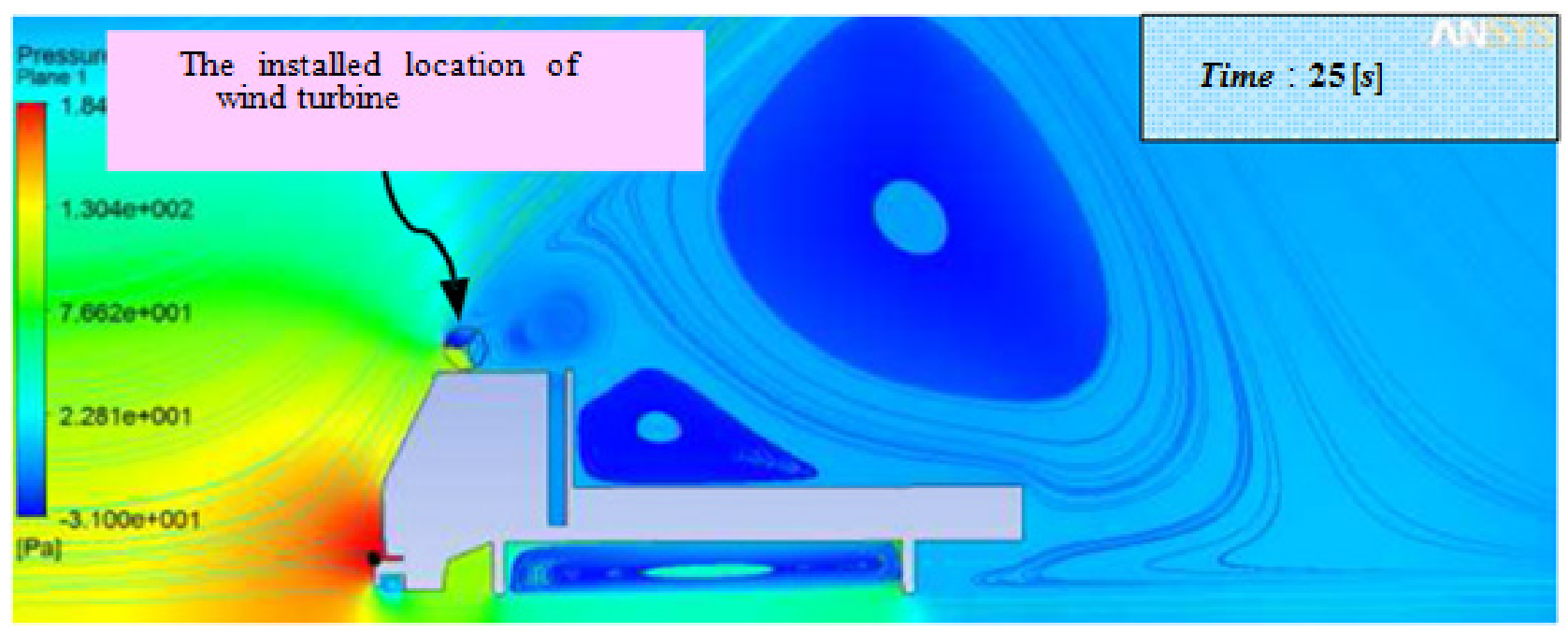

(a)

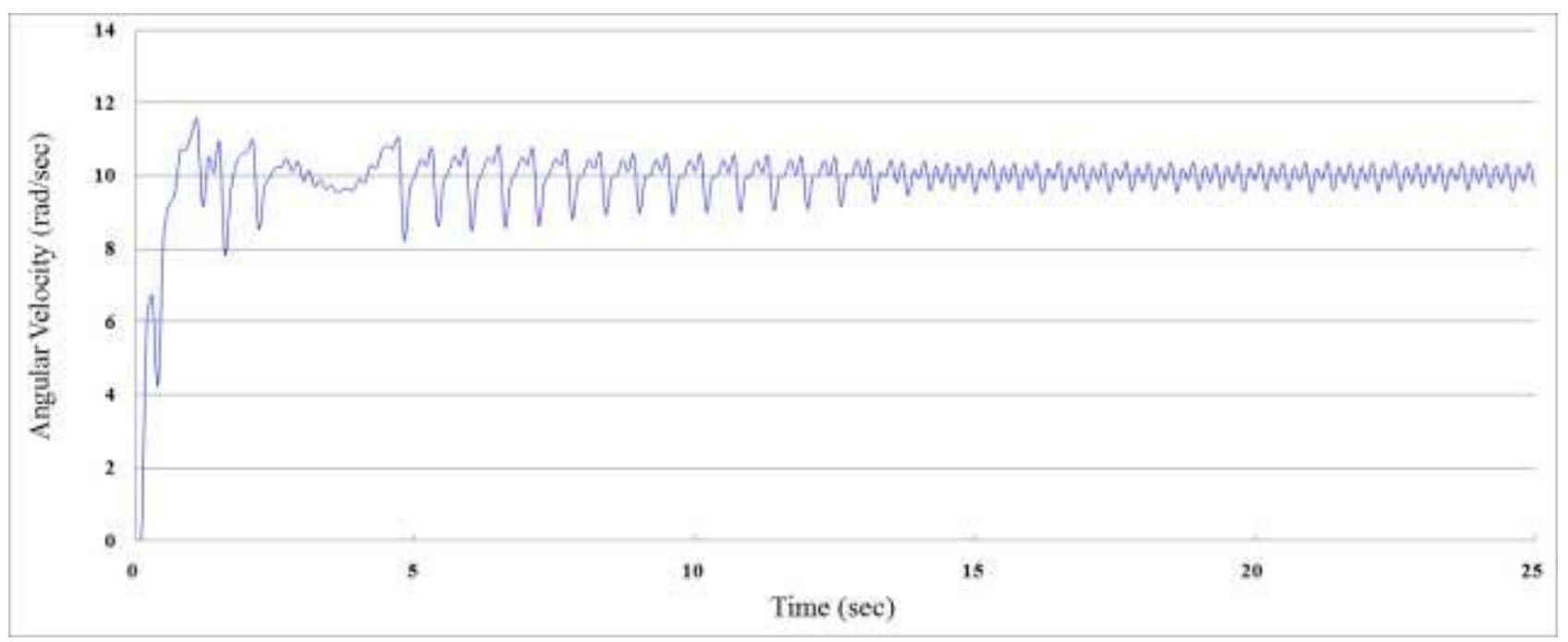

(b)

Figure 11. Turbine installed in the front roof: (a) the pressure and streamline diagram, (b) the angular speed

From the flow field of simulation Case 1 and Case 2 in Figures 10 and 11, it is clearly shows that the wind stream is very low and the flow field is very complex. In addition, there are several explicit vortexes at the top and the rear of the vehicle because of the differential pressure. Figure 10(b) shows the angular speed of wind turbine drops to zero which means the wind turbine does not rotate any more. That is, the wind power installed in the rear roof does not generate any electricity. On contradiction, the angular speed of wind turbine in the front roof is very stable and strong, shown in Figure 11(b). That is, because the blades stay in the high wind speed area of the outside main streamline field flow, the rotor angular speed is up to about 10rad/s (about 95.5rpm). However, because the flow field at the roof of vehicle is affected by the vortex at the rear roof of vehicle, it causes the tail flow of the wind turbine cannot be dissipated in the rear. It leads the diversion of the backflow and the main streamline force on blades with the opposite direction simultaneously, as shown in Figure 12. It causes the speed of wind turbine only can reach $95.5 \mathrm{rpm}$. It explains that the efficiency is only 0.1 though the wind power system installed in the top roof of vehicle can generate electricity better than the one in the rear roof. 


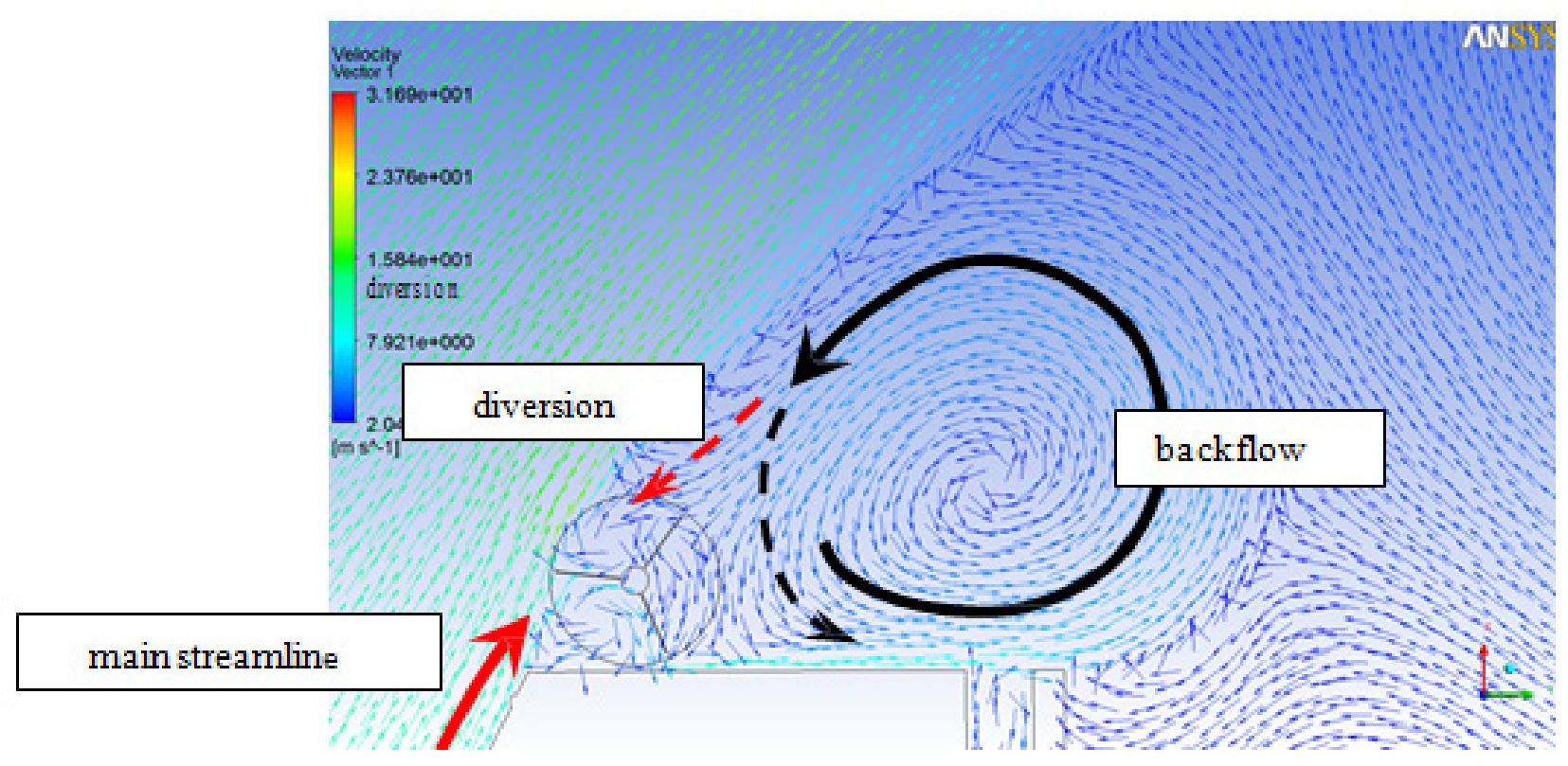

Figure 12. Backflow effect of wind turbine in front of vehicle

According to the final report of ITRI energy consuming efficiency promotion project, it claimed that, with appropriate installation of wind deflector, the coefficient of wind drag could be deduced about 30\% [21]. In Case 3, the wind power system in rear roof and a deflector were installed. There is a $19 \mathrm{~cm}$ air inlet duct on the deflector to guide the airflow in.

Case 3: the wind turbine is installed in the rear with a deflector.

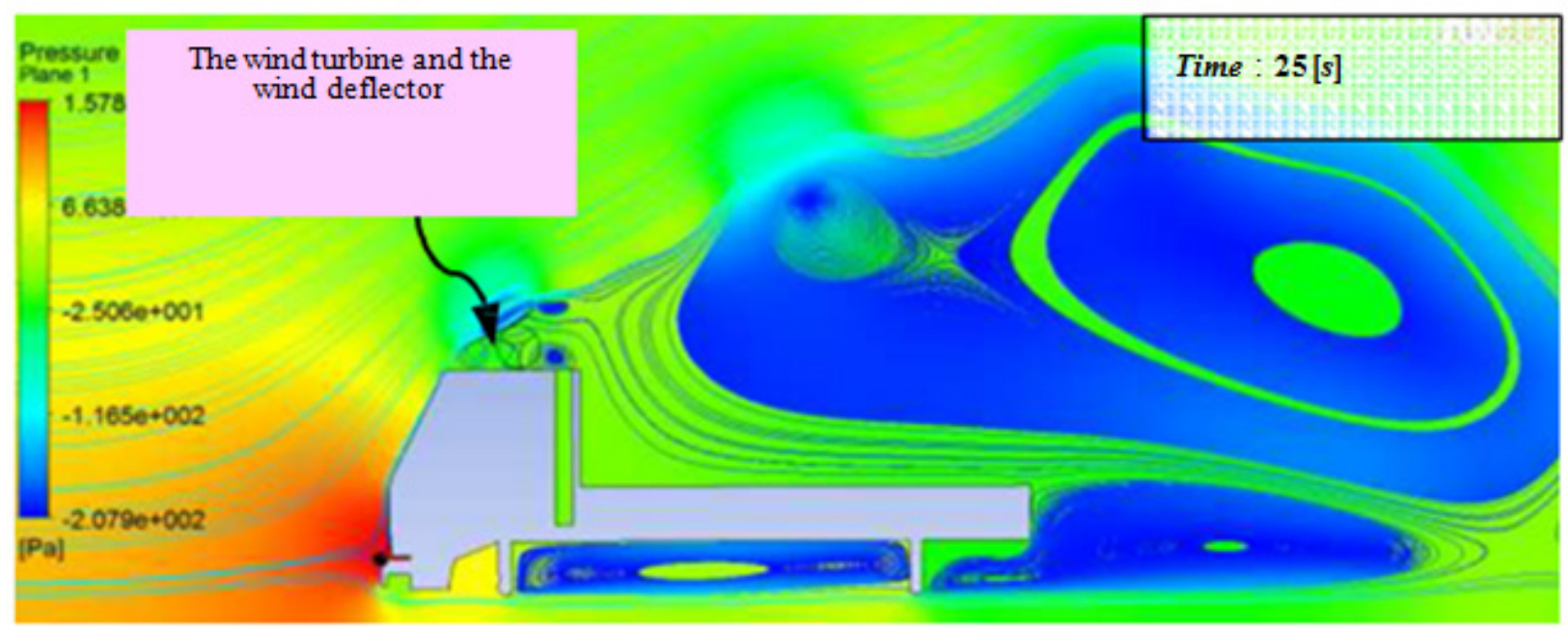




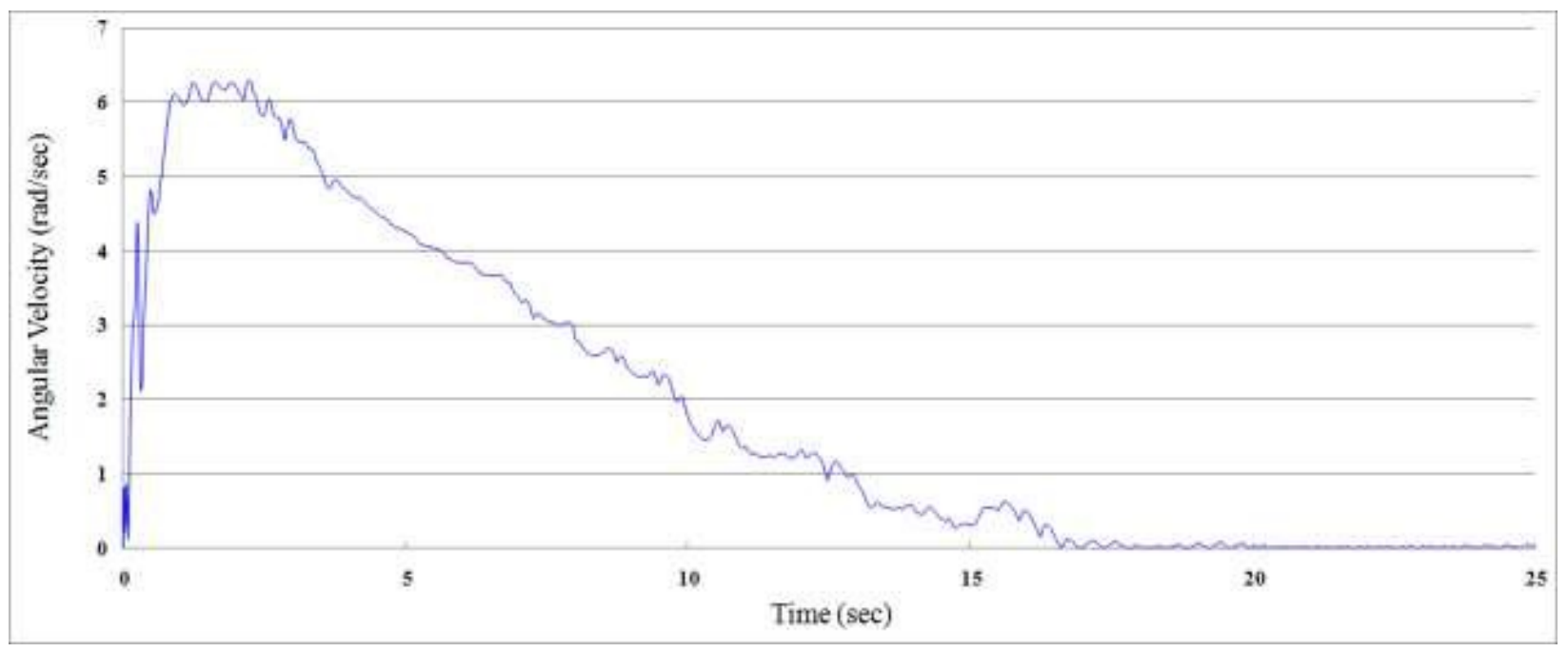

(b)

Figure 13. Turbine installed in the rear with deflector: (a) the pressure and streamline diagram, (b) the angular speed

The result of Case 3 is shown in Figure 13. It shows that the wind turbine cannot operate after installing the wind deflector. Contrarily, the airflow becomes more unstable. Hence, the geometry of the wind deflector is modified according to the curve of the main streamline to increase the length of the wind deflector. The inlet duct is modified with a cross-section width $16.5 \mathrm{~cm}$ air inlet guide. Case 4 is the wind power system installed in rear roof with the air inlet guide wind deflector. Case 5 is the wind power system installed in the front roof with the air inlet guide wind deflector. The results of Cases 4 and 5 are shown in Figures 14 and 15. It indicates that the rotors' angular speeds of Case 4 and Case 5 are none. That is, the rotors are stationary, don't rotate. Because the main streamlines entered into the air inlet, and passed through the bottom of the rotor. It forms two backflows in opposite directions. These opposite backflows act on the blades simultaneously. Thus, the blades are not able to rotate.

Case 4: the wind turbine installed at the rear roof with the air inlet guide wind deflector.

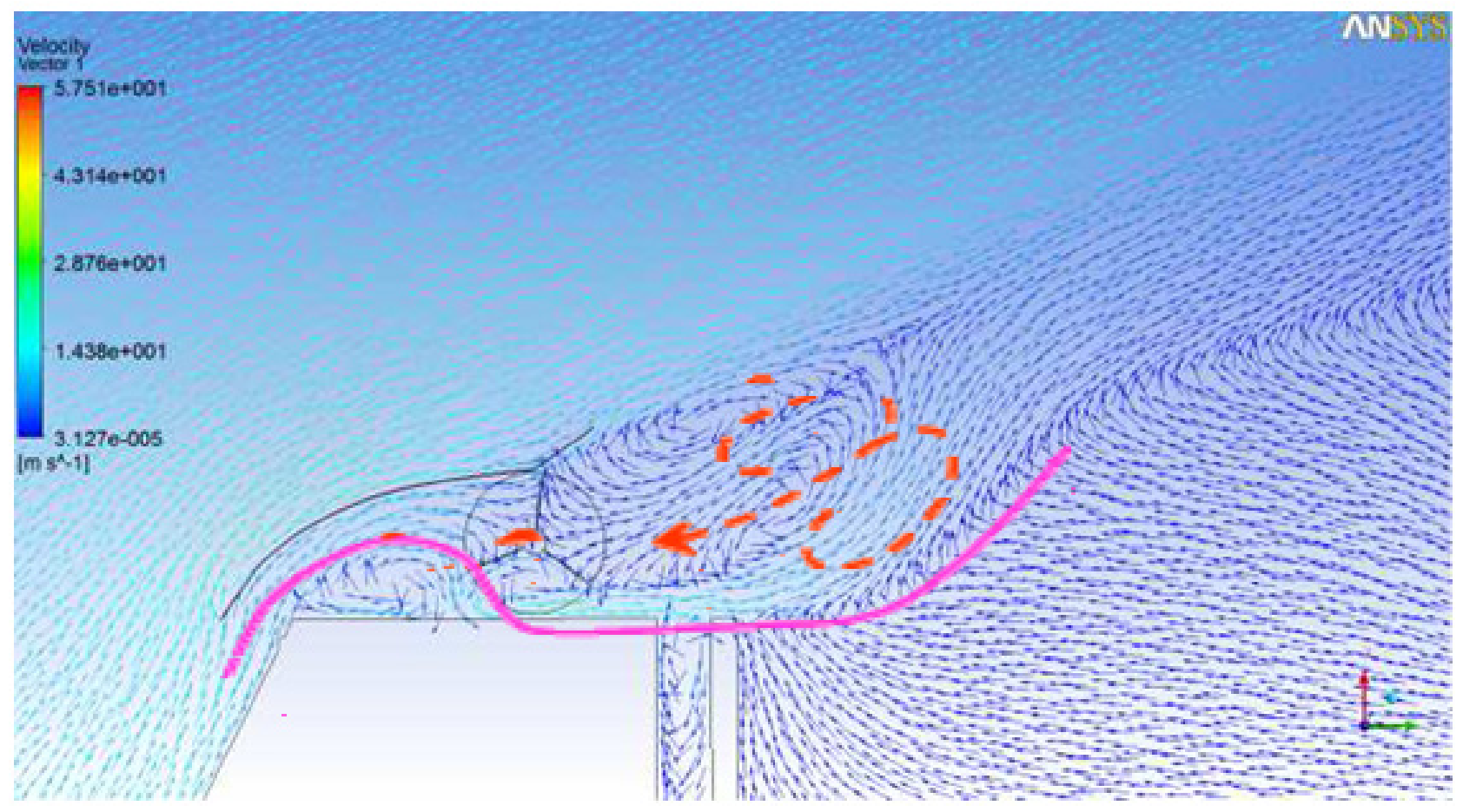




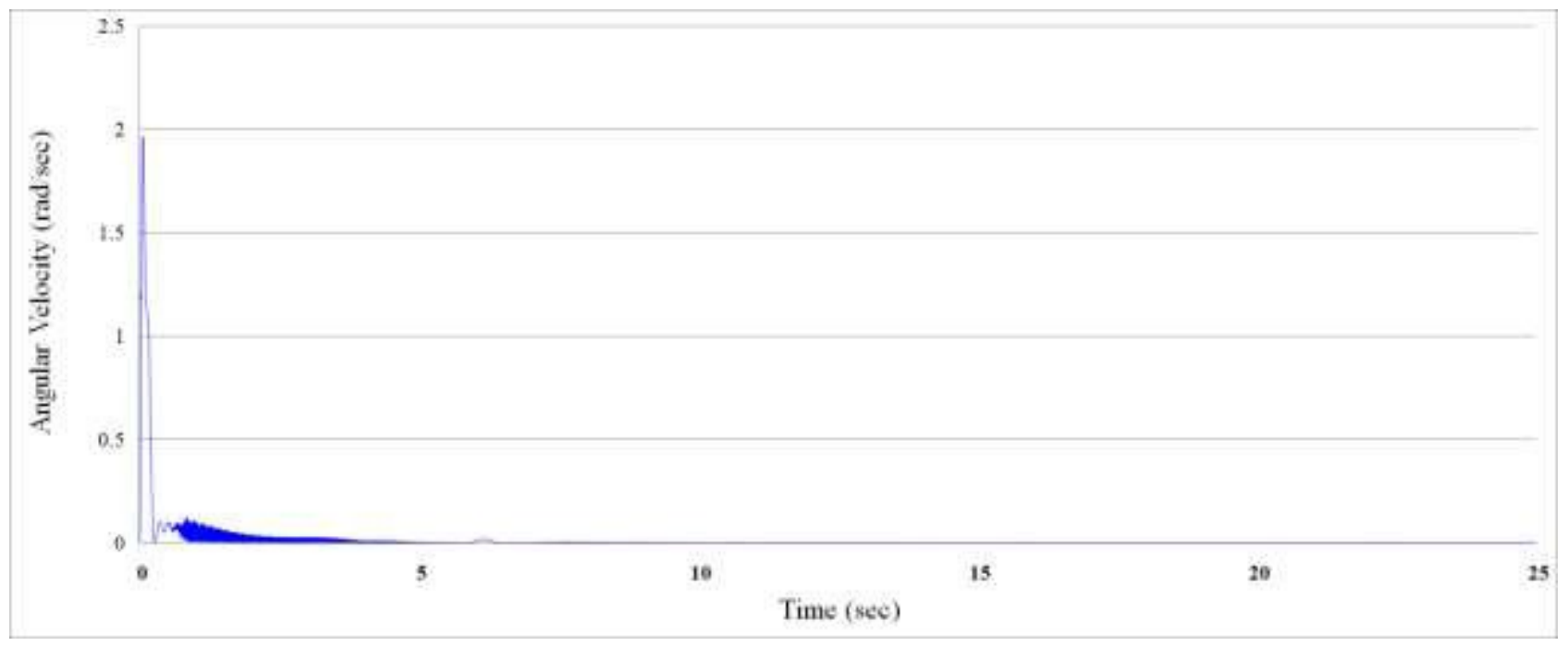

(b)

Figure 14. Turbine installed at the rear roof with the air inlet guide wind deflector: (a) the pressure and streamline diagram, (b) the angular speed Case 5: the wind turbine installed in front roof with the air inlet guide wind deflector.

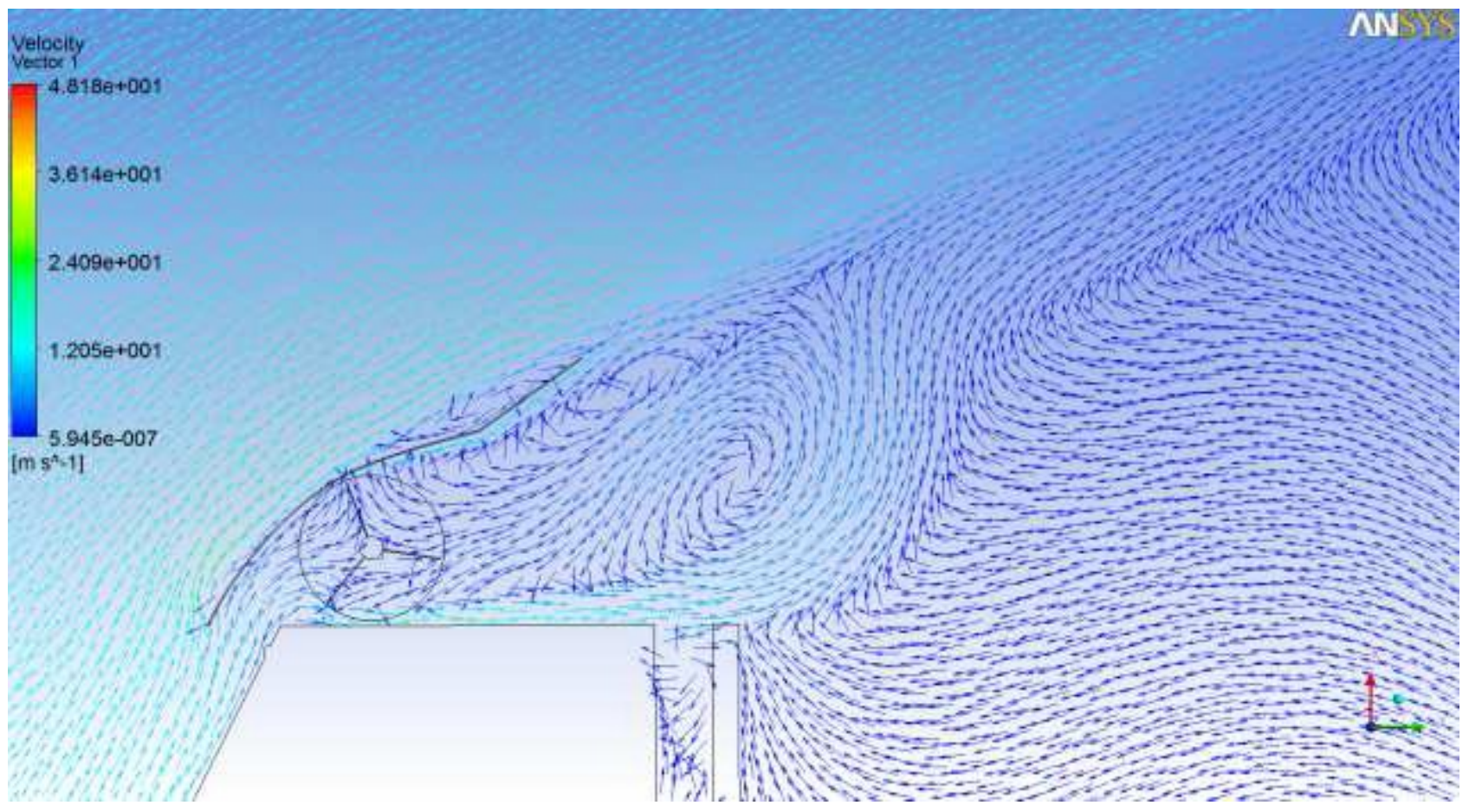

(a) 


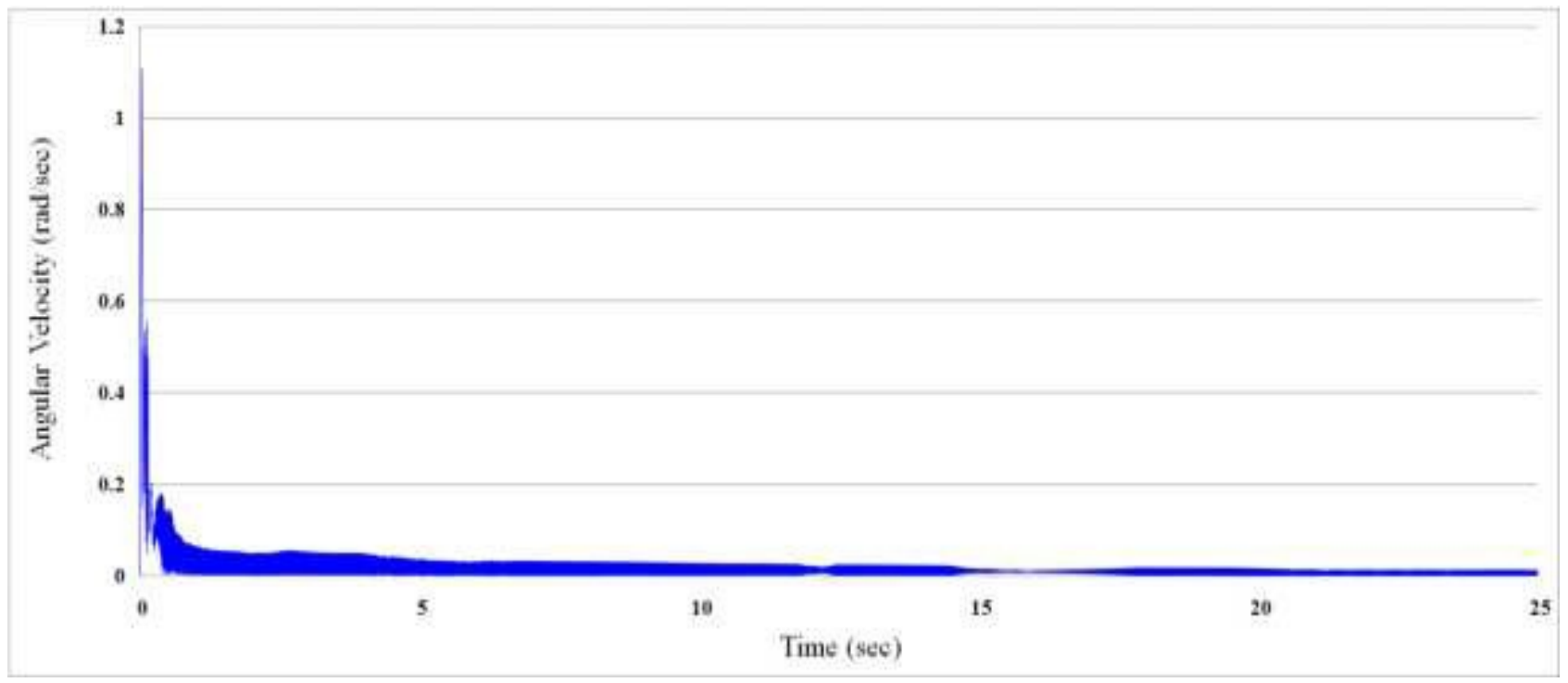

(b)

Figure 15. Turbine installed at the front roof with the air inlet guide wind deflector: (a) the pressure and streamline diagram, (b) the angular speed

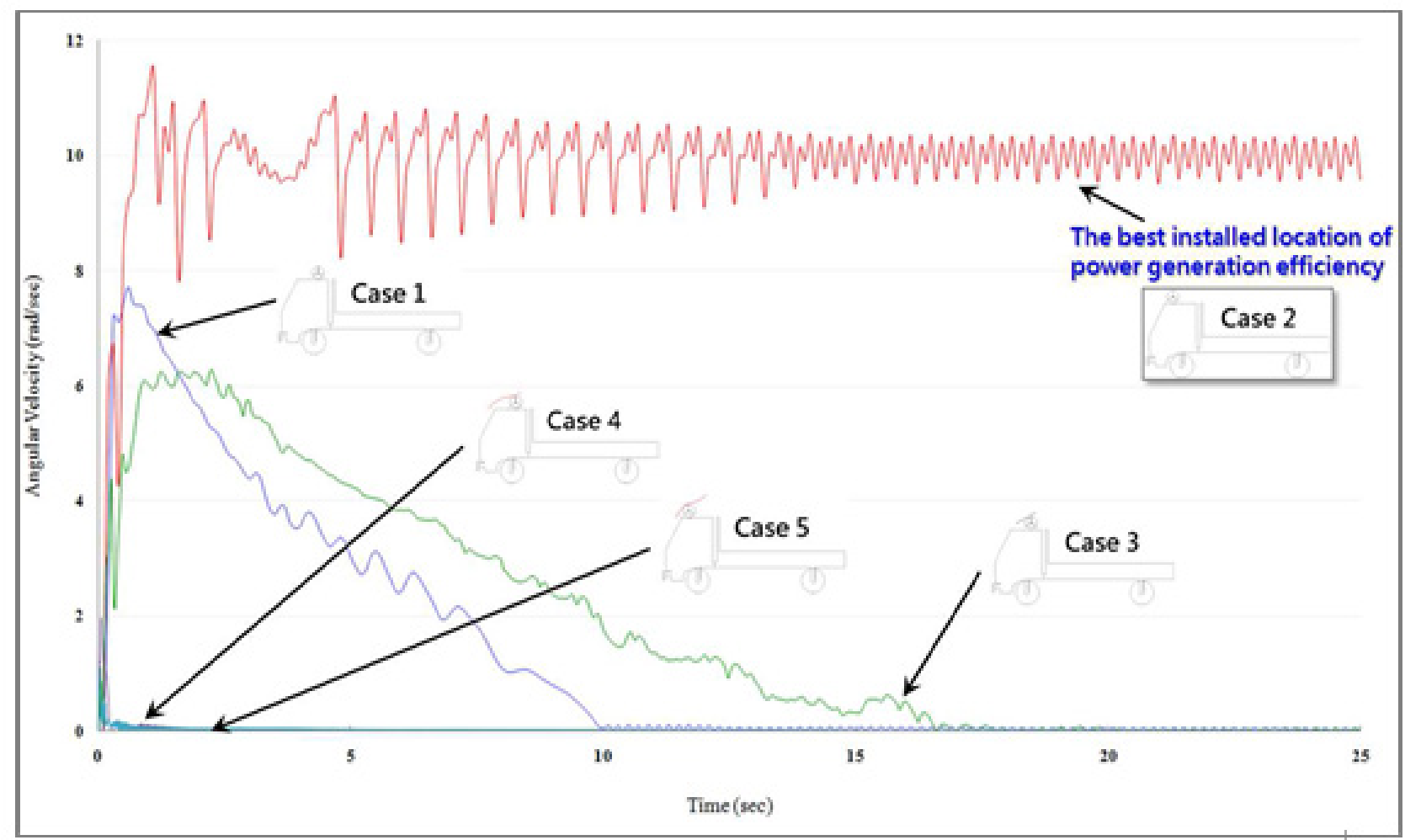

Figure 16. Comparison diagram of wind turbine rotor angular speeds for five cases

The above section discusses the details of the numerical analysis of the wind power system with different installation locations, with air deflectors, and with air inlet guide. The comparison of results is shown in Figure 16. It indicates that the install location and the distribution of field flow speed are the major factors for applying the wind power system on the vehicle. The numerical simulation shows that the best installation location of the wind power system is in the front roof of a vehicle.

\section{Conclusions}

In this study, a wind power system on vehicle was developed and tested. A series of numerical simulations were carried out to analyze and evaluate the field flow speed and the installation location of wind power system. The CFD numerical and experimental results show that:

1. When the moving vehicle generates enough relative wind speed, the proposed wind power system is able to 
generate electricity in any seasons and any weather conditions. The proposed wind power system on vehicle is able to generate up to $300 \mathrm{Watts}$ electric power when the wind speed reaches $82.5 \mathrm{~km} / \mathrm{hr}$.

2. The install location and the distribution of field flow speed are the major factors for applying the wind power system on the vehicle. The numerical simulation shows that the best installation location of the wind power system is in the front roof of a vehicle.

3. The problem of the higher cut-in wind speed and the dynamic equilibrium can be improved by using the resin transfer molding technique or die-forging of alloy material. These techniques can be used to solve the effect of the uneven weight of the blade cross-section. With the lightweight of wind power system, the efficiency can be increased, too.

\section{Acknowledgements}

The authors express their thanks to Chung-Shan Institute of Science and Technology for financial and technical supports in this study under the grant no.XD99165P158PE.

\section{REFERENCES}

[1] MOEA Bureau of Energy, 2009, "Energy Indicators of Taiwan (078 098),"

http://www.moeaboe.gov.tw/opengovinfo/Plan/all/energy_ye ar/main/EnergyYearMain.aspx?PageId=default.

[2] Wu, R.H., 2009, “The Energy Security Setting System in Our Country," Energy Report, Vol.5, pp.8-10.

[3] Topology Research Institute, 2009, "From the Perspective of Green Vehicles Toward the Opportunity of Electric Vehicle Development,"Vol. 3, pp.11-12.

[4] MOTC Department of Statistics, 2010, http://www.motc.gov.tw/motchypage/hypage.cgi?HYPAGE= stat07.asp \& catid $=429 \&$ year $=98$

[5] WWF, Ecofys, "The Energy Report: 100\% Renewable Energy by $2050, "$

[6] World Wind Energy Association(WWEA), 2010, "World Wind Energy Report 2009,"

[7] Renewable Energy Policy Network for the 21st Century(REN21), "Renewables 2010 Global Status Report," [8] Hung, C.Y., 2005, "A Study on Wind Power System Used in Automotive Charging System," Master's Thesis,

[8] National Taiwan Normal University, Taiwan.

[9] Cheng, W.P., 2005, "Design of Wind Power System to Improve Energy Efficiency and Electric Power Stability of Vehicle," Master's Thesis, National Taipei University of Technology, Taiwan.

[10] Greenbird,http://www.greenbird.co.uk/

[11] Trans Scan, 2008, "Using wind power to stable transport costs," Vol. 9, No. 3.

[12] Wind Explorer, http://www.wind-explorer.com/

[13] MOTC, http://www.motc.gov.tw/

[14] Taiwan Patent Search, http://twpat.tipo.gov.tw/

[15] United States Patent and Trademark Office (USPTO), http://www.uspto.gov/

[16] Shiau, Y.J., 2009, "TRIZ Keys to Technical Innovation," Cubic Creativity Co., Ltd., Taipei.

[17] J.F Manwell, J.G. McGowan and A.L. Rogers, 2002, "Wind Energy Explained Theory, Design and Application," John Wiley and Sons Ltd., New York.

[18] U.K. Saha, and M. Jaya Rajkumar, 2006, "On the Performance Analysis of Savonius Rotor with Twisted Blades," Renewable Energy Vol. 31, 1776-1788.

[19] M.A. Kamoji, S.B. Kedare, and S.V. Prabhu, 2009, "Performance Tests on Helical Savonius Rotors," Renewable Energy Vol. 34, 521-529.

[20] Chang, W.J., 2010, "Unsteady Flow Simulation of Startup Process of Thevertical Axis Wind Turbine," Master's Thesis, China University of Science and Technology, Taiwan.

[21] Auto Energy Website, "The Wind Deflector on Truck Toward the Effect of Drag and Fuel Consumption,"http://auto.itri.org.tw/research/DOC/menu5 23. pdf 